\title{
Brain-Derived Neurotrophic Factor Reduces Amyloidogenic Processing through Control of SORLA Gene Expression
}

\author{
Michael Rohe, ${ }^{1}$ Michael Synowitz, ${ }^{2}$ Rainer Glass, ${ }^{1}$ Steven M. Paul, ${ }^{3}$ Anders Nykjaer, ${ }^{4}$ and Thomas E. Willnow ${ }^{1}$ \\ ${ }^{1}$ Max Delbrueck Center for Molecular Medicine and ${ }^{2}$ Department of Neurosurgery, Charité-Universitätsmedizin Berlin, D-13125 Berlin, Germany, ${ }^{3}$ Lilly \\ Research Laboratories, Indianapolis, Indiana 46225, and ${ }^{4}$ The Lundbeck Foundation Research Center MIND, Department of Medical Biochemistry, Aarhus \\ University, DK-8000C Aarhus, Denmark
}

Sorting protein-related receptor with A-type repeats (SORLA) is a major risk factor in cellular processes leading to Alzheimer's disease (AD). It acts as sorting receptor for the amyloid precursor protein (APP) that regulates intracellular trafficking and processing into amyloidogenic- $\beta$ peptides $(\mathrm{A} \beta)$. Overexpression of SORLA in neurons reduces while inactivation of gene expression (as in knock-out mouse models) accelerates amyloidogenic processing and senile plaque formation. The current study aimed at identifying molecular pathways that control SORLA gene transcription in vivo and that may contribute to low levels of receptor expression in the brain of patients with $\mathrm{AD}$. Using screening approaches in primary neurons, we identified brain-derived neurotrophic factor (BDNF) as a major inducer of Sorla that activates receptor gene transcription through the ERK (extracellular regulated kinase) pathway. In line with a physiological role as regulator of Sorla, expression of the receptor is significantly impaired in mouse models with genetic $\left(B d n f^{-/-}\right)$or disease-related loss of BDNF activity in the brain (Huntington's disease). Intriguingly, exogenous application of BDNF reduced A $\beta$ production in primary neurons and in the brain of wild-type mice in vivo, but not in animals genetically deficient for Sorla. These findings demonstrate that the beneficial effects ascribed to BDNF in APP metabolism act through induction of Sorla that encodes a negative regulator of neuronal APP processing.

\section{Introduction}

SORLA is a member of the VPS10P domain receptor family, a group of sorting receptors involved in regulated neuronal protein transport (for review, see Willnow et al., 2008). SORLA is a 250 $\mathrm{kDa}$ protein widely expressed in neurons in cortex, hippocampus, and cerebellum. A possible link between this receptor and Alzheimer's disease (AD) was suggested by findings that SORLA gene expression is drastically reduced in the brain of patients suffering from the sporadic form of the disease (Scherzer et al., 2004; Dodson et al., 2006). This initial observation was further substantiated by genetic evidence showing an association of SORLA gene variants with risk of AD in several population-based investigations (Lee et al., 2007; Rogaeva et al., 2007; Bettens et al., 2008).

The molecular mechanism of SORLA action in neurodegenerative processes was revealed in a number of studies in cell culture and mouse models. According to these studies, SORLA acts as an intracellular sorting receptor for the amyloid precursor protein (APP) that controls trafficking of APP between trans-

\footnotetext{
Received Aug. 13, 2009; revised 0ct. 15, 2009; accepted 0ct. 29, 2009.

This work was funded in part by grants from the Lundbeck Foundation, the European Commission (MEMORIES), the Helmholtz-Association, and the Alzheimer Forschungsinitiative Cologne. We are indebted to M. Schmeisser for expert technical support, and to V. Schmidt and A.-S. Carlo for critical reading of the manuscript.

Correspondence should be addressed to either of the following: Thomas E. Willnow, Max Delbrueck Center for Molecular Medicine, Berlin, R.-Rössle-Strasse 10, D-13125 Berlin, Germany, E-mail: willnow@mdc-berlin.de; or Anders Nykjaer, Department of Medical Biochemistry, Ole Worms Allé, Building 1170, Aarhus University, DK-8000C Aarhus, Denmark, E-mail: an@biokemi.au.dk.

DOI:10.1523/JNEUROSCI.3960-09.2009

Copyright $\odot 2009$ Society for Neuroscience ～0270-6474/09/2915472-07\$15.00/0
}

Golgi network (TGN) and early endosomes (Andersen et al., 2005). In particular, SORLA blocks transport of APP into intracellular compartments that harbor $\beta$-secretase activity and thus impairs processing into the amyloid $\beta$ peptide $(A \beta)$, the main constituent of senile plaques (Andersen et al., 2005; Schmidt et al., 2007). Consequently, overexpression of SORLA in cultured cells results in reduced processing of APP into A $\beta$ (Andersen et al., 2005; Offe et al., 2006). In contrast, disruption of the receptor gene in mouse models of $\mathrm{AD}$ significantly increases $\mathrm{A} \beta$ production and plaque formation (Dodson et al., 2008; Rohe et al., 2008), similar to the situation in patients with sporadic AD.

Little is known about the physiological signals that control SORLA expression and activity in the brain. The aim of the present study was to identify factors that regulate expression of Sorla in neurons and that may play a decisive role in neurodegenerative processes. Intriguingly, we identified BDNF as a major regulator of Sorla transcription in primary neurons and in the brain in vivo. Loss of BDNF expression under pathological conditions [as in the striatum of mouse models of Huntington's disease (HT) ] or after gene targeting (as in $B d n f^{-1-}$ mice) significantly impairs Sorla expression. On the other hand, exogenous application of BDNF in primary neurons and in the mouse brain in vivo raises SORLA levels and thereby impedes amyloidogenic peptide formation.

\section{Materials and Methods}

Reagents. Growth factors and neurotrophins were obtained commercially: BDNF, ciliary neurotrophic factor (CNTF), vascular endothelial growth factor (VEGF), and fibroblast growth factor (FGF) (Tebu-bio); 
connective tissue growth factor (CTGF) (BioVision); nerve growth factor (NGF) (Invitrogen); platelet-derived growth factor (PDGF) (Axxora); and epidermal growth factor (EGF) (Promega). Antisera and inhibitors were purchased from commercial suppliers: anti-tubulin (Sigma); antiTrkB, anti-phosphorylated TrkB, anti-phosphorylated AKT, antiphosphorylated extracellular regulated kinase (ERK), anti- $\beta$ tubulin, U0126, and LY294002 (Cell Signaling Technology); DAPT (Calbiochem); and anti-synaptophysin (Synaptic Systems). Anti-SORLA and anti-sortilin IgG were provided by Claus M. Petersen (Aarhus University, Aarhus, Denmark). Anti-APP 1227 was generated in-house.

Mouse models. The generation of the PDAPP line (Games et al., 1995), as well as BDNF-, NGF-, and SORLA-deficient mouse models, has been described before (Crowley et al., 1994; Ernfors et al., 1994; Andersen et al., 2005). The Huntington mouse model (HD82) was a gift from Erich Wanker (Max Delbrueck Center for Molecular Medicine, Berlin, Germany) (Schilling et al., 1999).

Primary neuronal cultures. Primary cortical neurons were prepared from newborn mice. Cortices were dissected in HBSS $\left(4^{\circ} \mathrm{C}\right)$, cells were dissociated using papain $\left(1 \mathrm{~h}\right.$ at $\left.37^{\circ} \mathrm{C}\right)$ and plated on poly-D-lysine/ collagen-coated culture dishes. The cells were cultured for $4-5 \mathrm{~d}$ using Neurobasal-A medium (Invitrogen) including B27 supplement (Sigma), and GlutaMAX (Invitrogen). Subsequently, the cells were treated by replacing half of the culture medium with fresh medium containing the relevant growth factors for $24-72 \mathrm{~h}$. Where indicated, the medium also included $230 \mathrm{~nm}$ DAPT, $20 \mu \mathrm{M}$ U0126, or $50 \mu \mathrm{M}$ LY294002.

Osmotic minipump implantation. Osmotic minipumps (model 1007D; ALZET; Sigma) filled with BDNF in artificial CSF (aCSF) were implanted subcutaneously into the back of the mouse (5.7 $\mu \mathrm{g}$ of BDNF per day for $7 \mathrm{~d})$. A cannula connected through a catheter to the minipump was placed stereotactically in the right hippocampus (coordinates from bregma: $-1.64 \mathrm{~mm}$ anteroposterior, $-1.6 \mathrm{~mm}$ dorsoventral, and $+1.7 \mathrm{~mm}$ lateral) (Brain Infusion Kit II; Sigma). As negative control, only aCSF was administered. Animals were killed after $7 \mathrm{~d}$ of BDNF infusion.

Analysis of gene expression. Levels of mRNA were determined by quantitative RT-PCR using the ABI Prism 7000 Sequence Detection System. Samples were measured in triplicates, and calculations were performed using the ABI Prism 7000 SDS software (version 1.2). Values for Sorla and sortilin were normalized to GAPDH expression determined in parallel in the respective samples. The amounts of proteins expressed in cultured neurons or in the brain were determined using standard SDS polyacrylamide gel electrophoreses and Western blot analysis. Signals were quantified using Advanced Image Data Analyzer software version 3.51 (Raytest). Murine $\mathrm{A} \beta_{40}$ (IBL), human $\mathrm{A} \beta_{40}$ (BioSource), and human $A \beta_{42}$ (BioSource) were quantified using commercial ELISA kits according to manufacturer's instructions. All quantitative data are shown as mean value \pm SD. Statistical significance was determined using Kruskal-Wallis test followed by Dunn's multiple-comparison testing (unless specified otherwise).

\section{Results}

To identify regulators of SORLA gene expression, we cultured primary cortical neurons from newborn mice in the absence or presence of various growth factors and neurotrophins known to affect neuronal activities. These factors included NGF, BDNF, VEGF, CNTF, CTGF, FGF, PDGF, and EGF. Robust induction of SORLA mRNA levels was seen for BDNF after $24 \mathrm{~h}$ of incubation (Fig. 1A). No significant induction of gene expression by BDNF was noted for sortilin, a related VPS10P domain receptor (Fig. $1 A)$. Also, BDNF application did not affect transcription of a number of other genes tested here, including $\alpha$-actin, $\beta$-actin, and GAPDH (supplemental Fig. 1, available at www.jneurosci. org as supplemental material). Induction of Sorla transcription was long lasting and even seen after $48 \mathrm{~h}$ of incubation with BDNF, but also with CTGF under this condition (Fig. $1 B$ ). Incubation of neurons with BDNF did not affect the overall light microscopical appearance and viability of the cultured neurons compared to untreated control cells (supplemental Fig. 2, avail-
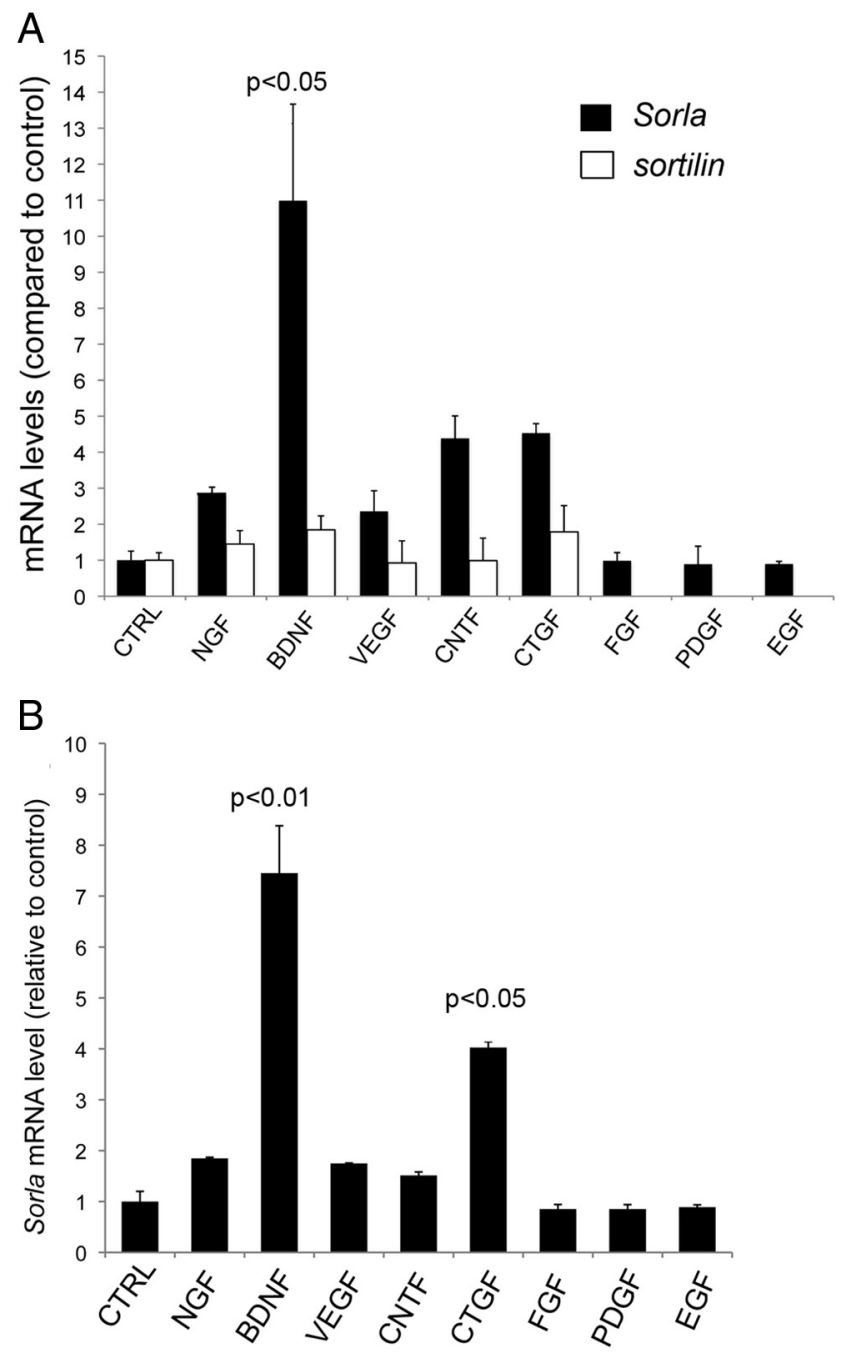

Figure 1. Induction of Sorla transcription in primary neurons by trophic factors. $\boldsymbol{A}$, Primary cortical neurons of newborn mice were incubated with $150 \mathrm{ng} / \mathrm{ml}$ of the indicated trophic factors. Twenty-four hours later, the amounts of mRNA for Sorla and sortilin were determined using quantitative RT-PCR and expressed as fold increase compared to cells incubated with medium only (CTRL, set at mRNA level 1). Values were normalized to GAPDH expression determined in parallel in the respective samples. $\boldsymbol{B}$, Quantitative RT-PCR of Sorla mRNA levels after $48 \mathrm{~h}$ of incubation with $150 \mathrm{ng} / \mathrm{ml}$ of the indicated trophic factors.

able at www.jneurosci.org as supplemental material). There was a tendency for slightly more extended branching of dendrites and more elongated axons in the BDNF-treated cultures as shown by staining for $\beta$-tubulin, a well known consequence of trophic support (supplemental Fig. 2, available at www.jneurosci.org as supplemental material). Elevated levels of the Sorla transcript translated into significantly higher levels of SORLA protein in primary neurons (Fig. $2 A$ ). This effect was particularly obvious for CTGF $(p<0.05)$ and BDNF $(p<0.001)$ (Fig. $2 A, B)$ and highly reproducible in numerous replicate experiments (supplemental Fig. 3, available at www.jneurosci.org as supplemental material). Based on the above evidence, we concluded that BDNF exerts a profound, long-lasting, and specific effect on neuronal expression of Sorla.

To investigate whether BDNF also represents a physiological inducer of Sorla in vivo, we tested receptor levels in the brain of mouse models with impaired BDNF expression. In newborn mice homozygous for a targeted BDNF gene disruption $\left(B d n f^{-1-}\right)$, the amount of SORLA in brain extracts was signifi- 

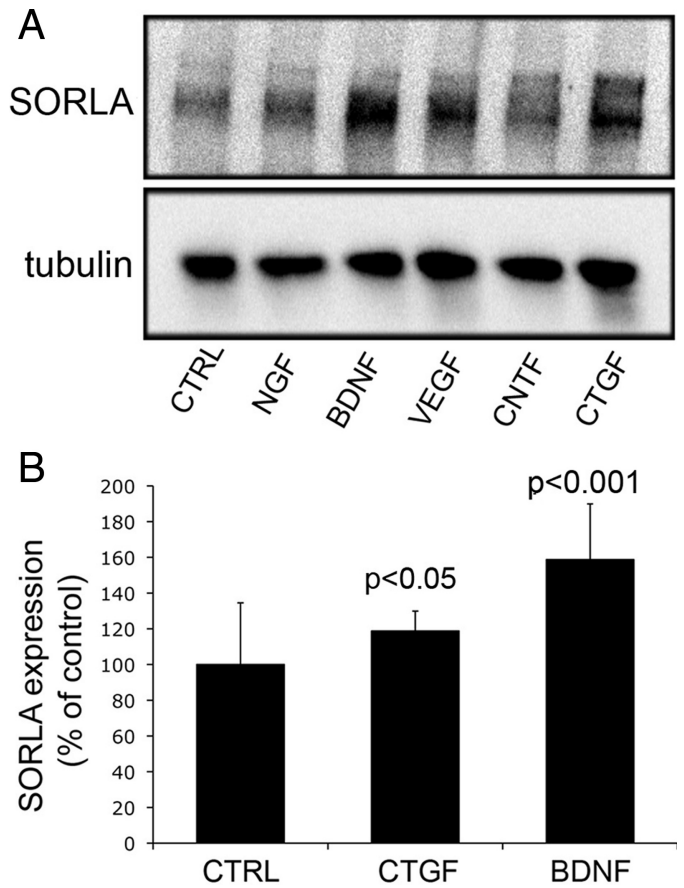

Figure 2. SORLA expression in primary neurons treated with trophic factors. $A$, Western blot analysis of SORLA expression in primary cortical neurons incubated for $3 \mathrm{~d}$ with medium (CTRL) or $150 \mathrm{ng} / \mathrm{ml}$ of the indicated trophic factors. Detection of tubulin served as loading control. $\boldsymbol{B}$, Densitometric analysis of four replicate experiments (individually shown in supplemental Fig. 3, available at www.jneurosci.org as supplemental material) indicates significant upregulation of SORLA protein levels following treatment of neurons with CTGF and BDNF.

A

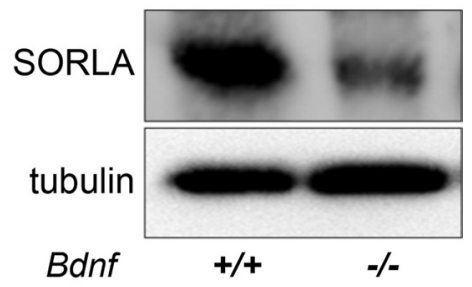

B

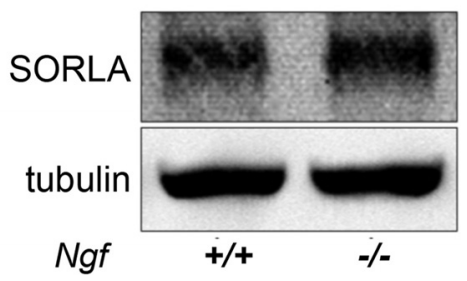

Figure 3. Reduced expression of SORLA in the Bdnf-targeted mouse models. Western blot analysis of SORLA expression in the brain of newborn mice genetically deficient for Bdnf $(\boldsymbol{A} ;-/-)$ or $\operatorname{Ngf}(\boldsymbol{B} ;-/-)$ compared with wild-type littermate controls $(+/+)$.

cantly reduced as shown by Western blot analysis (Fig. 3A). Densitometric scanning of replicate Western blots revealed a statistical significant reduction in relative receptor levels from $100 \pm 36.1 \%$ in newborn wild types $(n=7)$ to $61.9 \pm 18.7 \%$ in $B d n f^{-1-}$ littermates ( $n=6 ; p<0.05$, Student's $t$ test). In contrast, SORLA levels were not affected in mice homozygous for the Ngf-null allele (Fig. 3B).

In HT, levels of BDNF are distinctly reduced in the striatum of affected individuals (Ferrer et al., 2000; Spires et al., 2004). In line with a physiological role for BDNF as activator of SORLA gene expression, low levels of BDNF in the striatum of HT mice (Fig. $4 A$ ) coincided with significantly reduced amounts of SORLA

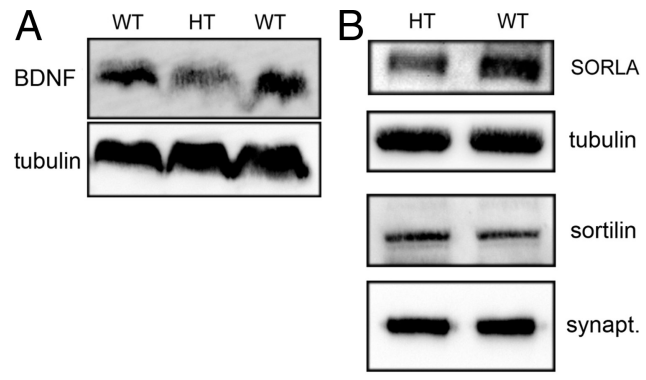

Figure 4. Reduced expression of SORLA in the striatum of mice with Huntington's disease. Western blot analysis of proteins expressed in the striatum of wild-type (WT) mice and of animals with HT. Reduced levels of BDNF in the HT mouse model $(\boldsymbol{A})$ coincides with impaired expression of SORLA but not sortilin or synaptophysin compared to the control animal $(\boldsymbol{B})$. Detection of tubulin served as loading control in both panels.

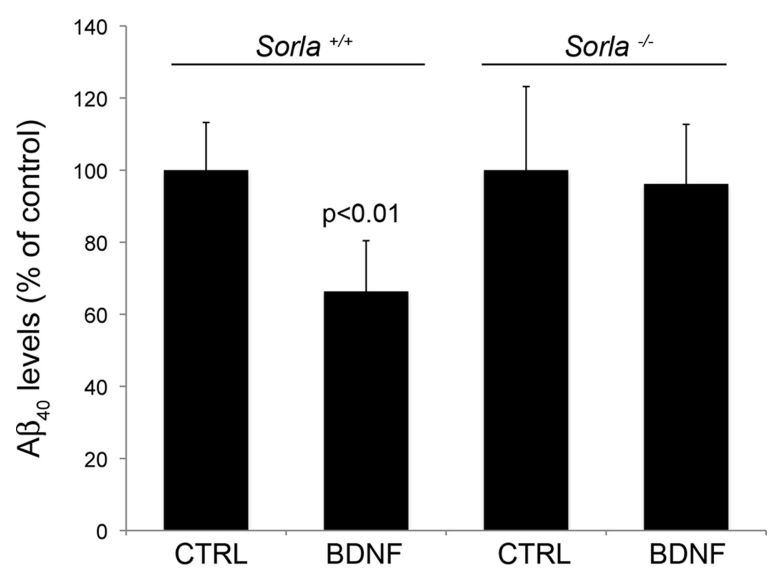

Figure 5. BDNF treatment reduces murine $A \beta$ production in wild-type but not in SORLAdeficient neurons. Primary cortical neurons of newborn mice were incubated with $150 \mathrm{ng} / \mathrm{ml}$ BDNF for $48 \mathrm{~h}$. Then, levels of $A \beta_{40}$ in the medium were determined by ELISA and expressed as percentage of control cells of the respective genotypes treated with medium only (CTRL; set at $100 \%)$. BDNF significantly reduces murine $A \beta_{40}$ production in wild-type $\left(\right.$ Sorla $\left.{ }^{+/+}\right)$but not SORLA-deficient neurons (Sorla ${ }^{-/-}$). $n=6-12$ per genotype.

protein in this brain region (Fig. $4 B$ ). Densitometric scanning of replicate Western blots revealed a statistical significant reduction in relative receptor levels from $100 \pm 26.1 \%$ in wild types $(n=4)$ to $56.0 \pm 21.6 \%$ in HT mice ( $n=5 ; p<0.05$, Student's $t$ test). Again, a correlation with BDNF levels was specific for SORLA and not seen for sortilin or synaptophysin that were expressed at normal levels in the striatum of the HT mouse model (Fig. 4B).

Given the established role of SORLA as negative regulator of APP processing, we wondered whether BDNF-mediated induction of receptor expression had an inhibitory effect on amyloidogenic processing in cultured neurons and in the brain in vivo. Thus, we treated primary cortical neurons from wild-type mice with BDNF, the neurotrophin that showed the most robust induction of SORLA expression. After $48 \mathrm{~h}$ of BDNF treatment, levels of murine $\mathrm{A} \beta_{40}$ dropped by $\sim 40 \%$ compared to untreated control neurons (Fig. 5). The inhibitory effect of BDNF on $\mathrm{A} \beta_{40}$ production was mediated through SORLA gene induction, as this effect was not seen in primary neurons from mice genetically deficient for the receptor $\left(\right.$ Sorla $^{-/-}$) (Fig. 5).

Lack of efficacy of BDNF in Sorla ${ }^{-1-}$ neurons was not due to impaired signaling of the neurotrophin as tested extensively in a number of experiments. Thus, we performed Western blot analysis for APP and the BDNF receptor TrkB in treated neurons. Chronic application of BDNF resulted in a similar reduction in 


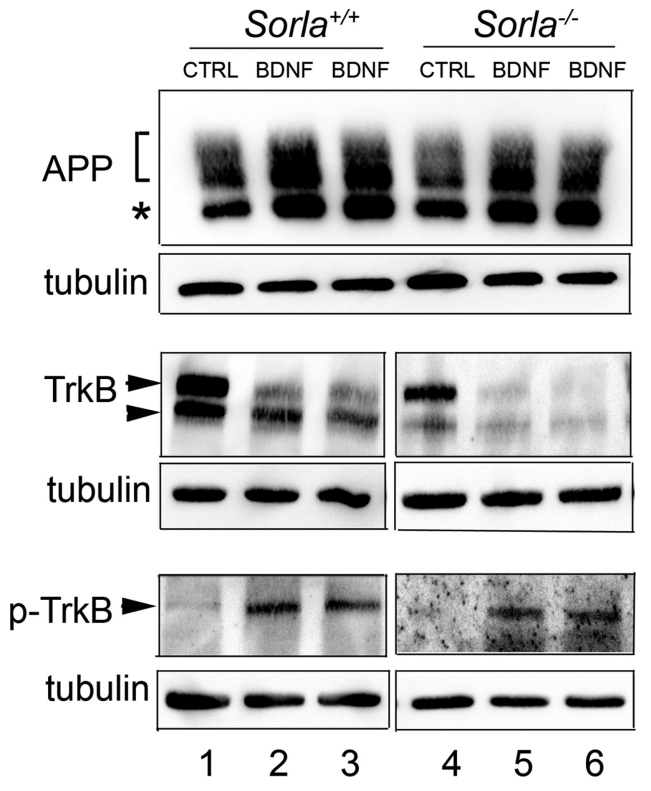

Figure 6. Expression of APP and TrkB in neurons treated with BDNF. Primary cortical neurons of newborn mice either wild-type $\left(S_{0 r l a}{ }^{+/+}\right.$; lanes 1-3) or genetically deficient for SORLA (Sorla ${ }^{-1-}$; lanes 4-6) were treated with control medium (CTRL; lanes 1,4) or medium containing $150 \mathrm{ng} / \mathrm{ml}$ BDNF (lanes 2, 3, 5, 6). After $48 \mathrm{~h}$, expression of APP, total TrkB, and phospho (p)-TrkB was tested by Western blot analysis in cell extracts of the various conditions. Detection of tubulin served as loading control. In panel APP, the mature form of the protein is indicated by the bracket, the immature form by the asterisk. Arrowheads indicate immunoreactive bands representing full-length and truncated forms of TrkB (panel TrkB) or phosphorylated TrkB (panel p-TrkB).

expression of total TrkB but a distinct increase in the active phosphorylated receptor variant (p-TrkB) in both genotypes (Fig. 6) (Knusel et al., 1997). As described previously (Ge and Lahiri, 2002; Ruiz-León and Pascual, 2004), application of BDNF also raised neuronal APP levels in our experimental conditions, an effect that was seen for both Sorla ${ }^{+/+}$and Sorla ${ }^{-1-}$ neurons (Fig. 6). In neurons, BDNF signals through a variety of intracellular mediators, including MAP and AKT kinase pathways (Reichardt, 2006). Short-term application of BDNF results in a robust activation of ERK and AKT, while long-lasting exposure of neurons stimulates ERK but not the AKT pathway (Fig. 7). Response to both transient (15 min) (Fig. 7A) and chronic (48 h) (Fig. 7B) treatments with BDNF was identical in primary neurons from wild-type and SORLA-deficient neurons as demonstrated by immunodetection of activated (phosphorylated) variants of AKT and ERK.

Together, our studies indicated that trophic actions on APP processing specifically work through induction of SORLA gene expression. Massive induction of Sorla (Fig. 8A) and a concomitant reduction in amyloid peptide production following BDNF treatment was also seen for human $\mathrm{A} \beta_{40}$ and $\mathrm{A} \beta_{42}$ in primary neurons from PDAPP mice, a mouse model that overexpresses a human APP gene variant (Fig. $8 B)(p<0.01)$ (Games et al., 1995).

A beneficial effect of BDNF on neurodegenerative disease progression in vivo is well appreciated (Schindowski et al., 2008; Tapia-Arancibia et al., 2008; Nagahara et al., 2009). To test whether this protective effect may be mediated in part through induction of SORLA expression, we treated mice with recombinant BDNF by intracranial injections into the hippocampus. After $7 \mathrm{~d}$ of $\mathrm{BDNF}$ application, the levels of murine $\mathrm{A} \beta_{40}$ in the hippocampus of treated animals were reduced by $>40 \%$

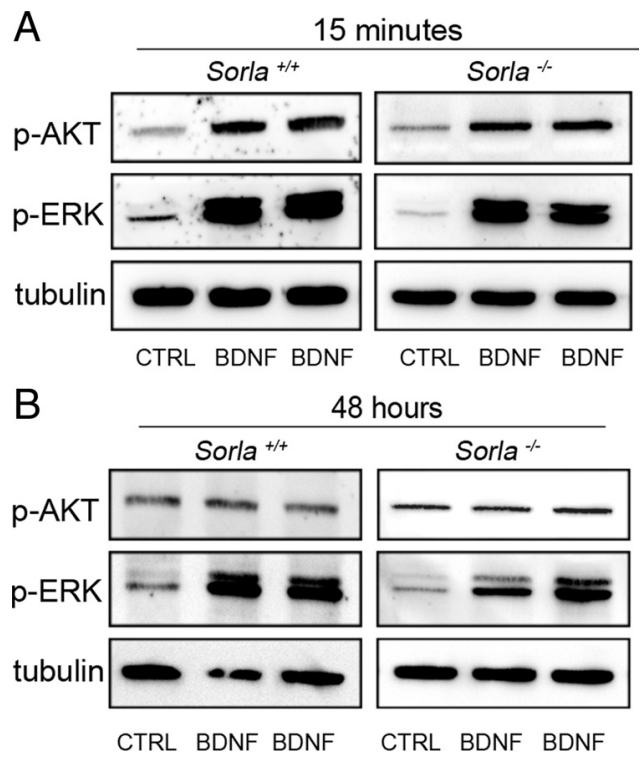

Figure 7. Activation of neuronal signaling pathways by BDNF. Primary cortical neurons of newborn mice either wild-type (Sorla ${ }^{+/+}$) or genetically deficient for SORLA (Sorla ${ }^{-1-}$ ) were treated with control medium (CTRL) or medium containing $150 \mathrm{ng} / \mathrm{ml}$ BDNF. Replicate cell layers were harvested after $15 \mathrm{~min}(\boldsymbol{A})$ or after $48 \mathrm{~h}$ of treatment $(\boldsymbol{B})$. Expression of phosphorylated variants of AKT ( $p$-AKT) and ERK ( $p$-EKT) was tested using Western blotting. Detection of tubulin served as loading control.
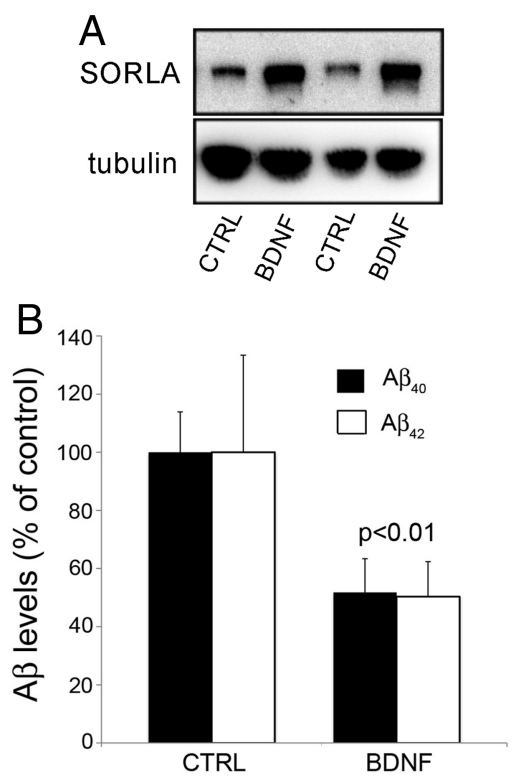

Figure 8. BDNF treatment reduces human $A \beta$ production in primary neurons. Replicate plates of primary cortical neurons of newborn PDAPP mice were incubated with $150 \mathrm{ng} / \mathrm{ml}$ BDNF for $48 \mathrm{~h}$. $A$, Subsequently, the amount of SORLA in BDNF treated or control (CTRL) cultures was determined by Western blot analysis. Detection of tubulin served as loading control. $B, A$ lso, levels of $A \beta_{40}$ (filled bars) and $A \beta_{42}$ (open bars) in the medium were determined by ELISA and expressed as percentage of control cells treated with medium only (CTRL; set at 100\%). BDNF treatment significantly reduces human $A \beta_{40}$ and $A \beta_{42}$ production. $n=14-15$ per condition.

compared to animals injected with artificial CSF only (Fig. 9) $(p<0.05)$. Intriguingly, the inhibitory effect of BDNF on amyloidogenic processing was absolutely dependent on the presence of the wild-type SORLA gene and not seen in BDNFtreated SORLA-deficient mice (Fig. 9).

Conceptually, activation of SORLA gene expression by BDNF may work through a number of mechanisms. For example, the 


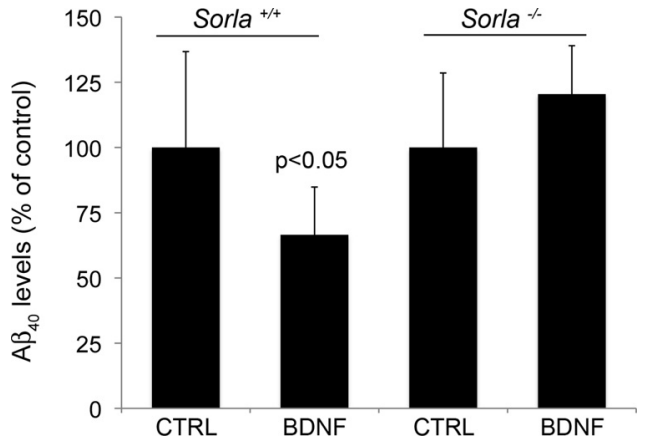

Figure 9. BDNF treatment reduces $A \beta$ production in the brain of wild-type but not of SORLA-deficient mice. Adult mice ( $n=8-11$ per genotype) were injected intracranially into the hippocampus for $7 \mathrm{~d}$ with a total dose of $40 \mu \mathrm{g}$ of recombinant BDNF. Thereafter, levels of $\mathrm{A} \beta_{40}$ in the hippocampus were determined and expressed as percentage of levels in control mice of the respective genotypes injected with artificial CSF (CTRL; set at 100\%). BDNF application significantly reduced $A \beta_{40}$ production in wild-type but not in SORLA-deficient mice.

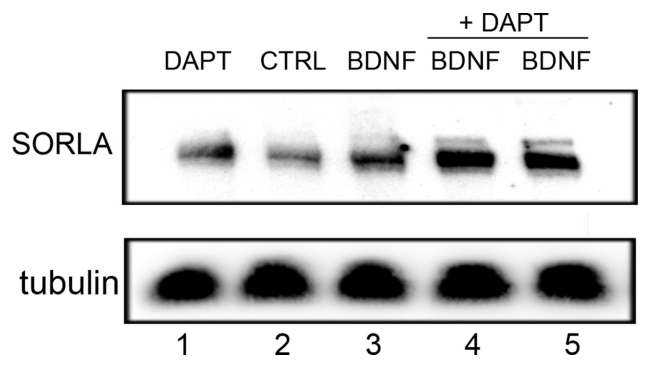

Figure 10. BDNF acts independent of $\gamma$-secretase to induce SORLA expression. Western blot analysis of SORLA expression in primary cortical neurons incubated for $2 \mathrm{~d}$ with medium (CTRL, lane 2), $230 \mathrm{~nm} \mathrm{DAPT} \mathrm{(lane} \mathrm{1),} \mathrm{or} 150 \mathrm{ng} / \mathrm{ml}$ BDNF in the presence (replicate incubations in lanes 4 and 5) or absence (lane 3) of DAPT. Detection of tubulin served as loading control.

intracellular domain (ICD) of SORLA is released by $\gamma$-secretasemediated cleavage (Nyborg et al., 2006) and acts as repressor of SORLA gene transcription (Böhm et al., 2006). Thus, BDNF may block $\gamma$-secretase activity, thereby reducing the amount of inhibitory SORLA ICD produced. Alternatively, BDNF may act through one of several intracellular signaling pathways to directly induce the receptor gene.

To explore the first hypothesis, we treated primary neurons with BDNF, with the $\gamma$-secretase inhibitor DAPT, or with both, and we tested their effects on SORLA protein levels $48 \mathrm{~h}$ later (Fig. 10). Application of DAPT blocked $\gamma$-secretase activity almost completely as confirmed by a massive reduction in $\mathrm{A} \beta_{40}$ production in this assay (CTRL: $100 \pm 6.9 \% \mathrm{~A} \beta_{40}$; DAPT treatment: $25.9 \pm 3.4 \% \mathrm{~A} \beta_{40}$ ). In line with previous reports (Böhm et al., 2006), inhibition of $\gamma$-secretase activity increased Sorla expression, likely by reducing the amount of SORLA ICD that represses the endogenous Sorla promoter (Fig. 10, lane 1). The level of induction was similar to that of BDNF tested in parallel (Fig. 10, lane 3). Remarkably, combined application of BDNF and DAPT enhanced SORLA expression even further (Fig. 10, lanes 4, 5), suggesting that both agents work through independent mechanisms. Thus, we concluded that BDNF acts independent of $\gamma$-secretase in regulation of Sorla transcription; the relevant mechanism likely involves transmembrane signaling. To identify the relevant signaling cascade, we stimulated neurons with BDNF in the presence of inhibitors of MEK (that acts upstream of ERK) and of PI3K (that acts upstream of AKT). As shown in Figure $11 A$, application of the MEK inhibitor U0126 impaired BDNFdependent activation of ERK as deduced from the drastically re-

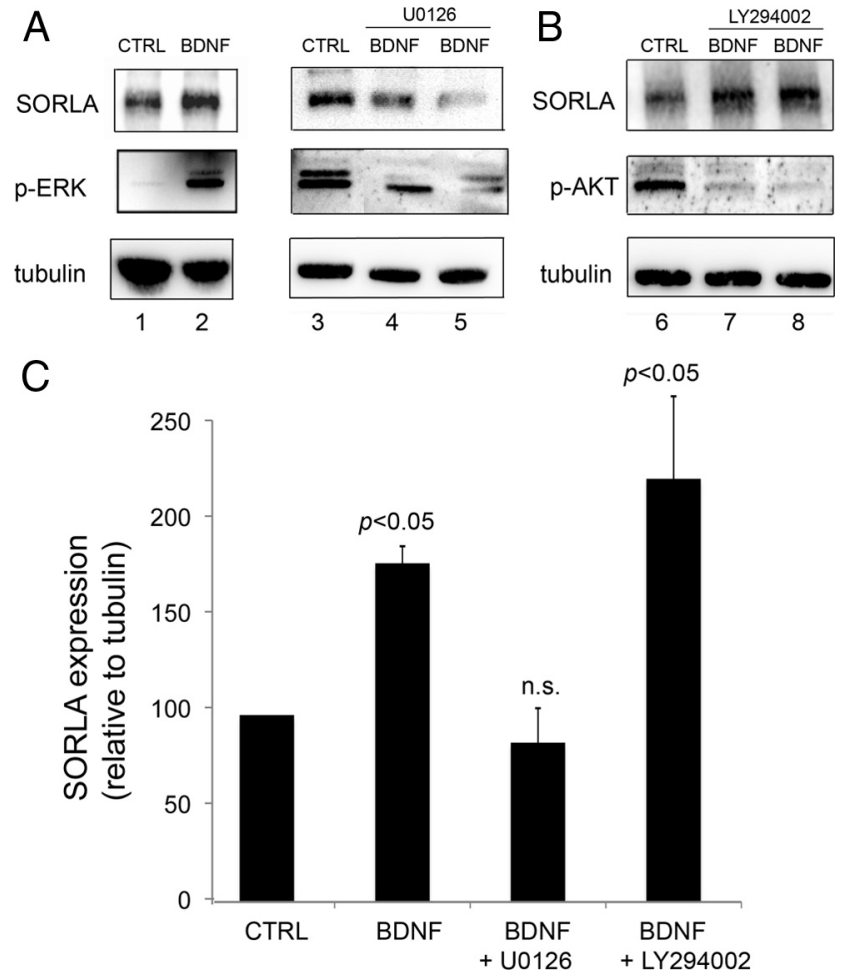

Figure 11. BDNF induces SORLA expression through MEK but not PI3K. $A, B$, Primary cortical neurons from wild-type mice were incubated with $150 \mathrm{ng} / \mathrm{ml}$ BDNF for $48 \mathrm{~h}$. Where indicated the media also contained $20 \mu \mathrm{M}$ MEK1/2 inhibitor U0126 or $50 \mu \mathrm{M}$ PI3 kinase inhibitor LY294002 (2 replicates per condition are shown). Expression of SORLA and phosphorylated variants of ERK ( $p$-ERK) and AKT ( $p$-AKT) was determined thereafter using Western blot analysis. Detection of tubulin served as loading control. Application of BDNF results in stimulation of p-ERK formation and a concomitant increase in SORLA levels ( $\boldsymbol{A}$; lane 2 ) compared to untreated cells $(\boldsymbol{A}$; lane 1$)$. Formation of $p$-ERK and induction of SORLA expression is not seen in cells treated with BDNF and U0126 ( $\boldsymbol{A}$; compare replicates in lanes 4 and 5 to control condition in lane 3). In contrast, induction of SORLA expression by BDNF is still seen in cells treated with LY294002 $(\boldsymbol{B}$; replicates in lanes 7 and 8 ) compared with controls ( $\boldsymbol{B}$; lane 6) despite a complete lack of p-AKT. C, Densitometric scanning of Western blot experiments exemplified in $\boldsymbol{A}$ and $\boldsymbol{B}(n=8)$ demonstrates loss of BDNF-induced SORLA expression in the presence of U0126 but not LY294002. SORLA levels relative to the tubulin loading control are expressed as percentage of untreated cells (set at 100\%). Statistical significance is shown for SORLA gene induction in the various conditions compared with nontreated control cells. n.s., Not significant.

duced amounts of p-ERK compared with control cells. Similarly, the addition of PI3K antagonist LY294002 blocked the formation of p-AKT following BDNF treatment (Fig. $11 \mathrm{~B}$ ). Application of the antagonists did not affect the overall cell viability as immunodetection of tubulin did not reveal any discernable difference comparing inhibitor-treated with untreated control neurons (Fig. $11 A, B$ ). Intriguingly, BDNF-stimulation of SORLA expression was blocked in cells treated with U0126. In contrast, gene induction was still observed in cultures treated with BDNF and LY294002 to the same extent as in controls cells incubated with BDNF only (Fig. 11C). This observation was confirmed in multiple replicate experiments $(n=8)$. Thus, MEK/ERK-dependent signals are responsible for BDNF-mediated Sorla induction.

\section{Discussion}

Our studies have identified a novel role for BDNF as physiological regulator of Sorla expression in neurons through stimulation of ERK. These findings suggest that induction of SORLA gene transcription may be part of the normal neurotrophic repertoire of BDNF in the brain. Also, some of the protective effects ascribed to BDNF activity in the AD brain may be attributed to its ability to 
raise levels of SORLA, the neuronal receptor that modulates APP trafficking and processing.

BDNF is a member of the family of neurotrophins, a group of secreted factors that regulate neuronal survival, target innervation, and synaptogenesis (Chao, 2003; Bothwell, 2006). Their trophic action is mediated by binding to receptor tyrosine kinases such as TrkB in case of BDNF. Binding of BDNF to TrkB results in ligand-induced receptor dimerization and kinase activation, and in the subsequent stimulation of downstream signaling pathways (Reichardt, 2006).

A number of distinct functions are attributed to BDNF action in the adult nervous system including regulation of activitydependent synaptic plasticity and a role in learning and memory (Linnarsson et al., 1997; Hall et al., 2000; Alonso et al., 2002). BDNF expression or lack thereof has also been associated with certain neurological disorders. For example, decreased expression of BDNF is seen in the substantia nigra in Parkinson's disease (Howells et al., 2000) and in the striatum in HT (Zuccato et al., 2001).

Because of its role in learning and memory formation, BDNF has been considered a critical factor in processes leading to $\mathrm{AD}$ related dementia. Foremost, levels of BDNF and its receptor TrkB are reduced in cortex and hippocampus of AD brains (NarisawaSaito et al., 1996; Connor et al., 1997; Siegel and Chauhan, 2000). Furthermore, BDNF gene variants are associated with risk of sporadic $\mathrm{AD}$ (Desai et al., 2005; Akatsu et al., 2006).

One of the main hypotheses concerning a role for BDNF in $\mathrm{AD}$ processes states that loss of trophic support as a consequence of reduced BDNF activity accelerates neuronal atrophy and loss of synapses (Tapia-Arancibia et al., 2008). In agreement with this model, application of BDNF by lentiviral somatic gene transfer into the entorhinal cortex reverses some of the pathological hallmarks of dementia in mouse models of $\mathrm{AD}$. It reduces loss of synapses, improves cell signaling (e.g., via ERK) and it partially restores learning and memory abilities (Nagahara et al., 2009). The beneficial effect of BDNF application was also confirmed in primates where it reversed neuronal atrophy and ameliorated age-related cognitive impairment (Nagahara et al., 2009).

A more direct effect of BDNF on molecular processes in $\mathrm{AD}$ has been proposed based on findings in primary hippocampal neurons. In these experiments, blockade of BDNF signaling by anti-BDNF antibodies increased $\mathrm{A} \beta$ formation and accumulation in neurons, and resulted in induction of neuronal cell death (Matrone et al., 2008). However, the molecular mechanism whereby BDNF may modulate APP processing remained unclear. Also, a proposed inhibitory effect of BDNF on $\mathrm{A} \beta$ production was questioned by findings that BDNF induces transcription of the APP gene, an effect that typically results in enhanced $A \beta$ production (Ge and Lahiri, 2002; Ruiz-León and Pascual, 2004).

The present study provides a molecular explanation for the inhibitory role of BDNF in APP processing because neurotrophin signaling leads to a potent and long-lasting induction of neuronal Sorla expression through the activation of MAP kinase pathways (Figs. 1, 11). Inactivation of the gene encoding SORLA completely eliminates the inhibitory effect of BDNF on $\mathrm{A} \beta$ production (Fig. 5), providing unequivocal genetic proof that BDNF acts via Sorla. Most importantly, the SORLA-dependent effect of $\mathrm{BDNF}$ on $\mathrm{A} \beta$ formation is not only seen in primary neurons in culture, but also in the brain of mice in vivo (Fig. 9). Based on previous studies from our and from other laboratories, increased expression of SORLA in cells causes sequestration of APP in the TGN and delays exit of the precursor into the secretory pathways, a prerequisite for proteolytic processing by secretases (Andersen et al., 2005; Schmidt et al., 2007). In line with previous reports, application of BDNF raised APP expression levels both in wildtype and Sorla ${ }^{-1-}$ neurons (Fig. 6) (Ge and Lahiri, 2002; RuizLeón and Pascual, 2004). However, the robust induction of SORLA expression completely blunted and even reversed the effect of elevated APP levels on A $\beta$ formation. These observations strongly support a profound role for this neuronal trafficking receptor in APP metabolism and AD progression.

In the adult brain, BDNF is mainly produced in the entorhinal cortex and hippocampus where it influences neuronal plasticity. At the cellular level, BDNF facilitates many processes including neurotransmitter release, glutamate-evoked postsynaptic responses, as well as long-term potentiation, just to name a few. Significant upregulation of Sorla transcription following BDNF treatment of neurons as well as loss of Sorla expression in mouse models with reduced BDNF activities indicates that BDNF is a physiological inducer of SORLA in the brain that acts via MAP kinases (but not through AKT). In which way SORLA activity may be relevant for BDNF-mediated processes in the CNS in vivo remains unclear at present. Elucidation of the underlying molecular mechanisms will be important for understanding the role of SORLA in neurotrophin action. Future studies may also reveal possible implications of reduced SORLA gene expression in diseases characterized by impaired BDNF activity such as Parkinson's and Huntington's disease.

\section{References}

Akatsu H, Yamagata HD, Kawamata J, Kamino K, Takeda M, Yamamoto T, Miki T, Tooyama I, Shimohama S, Kosaka K (2006) Variations in the BDNF gene in autopsy-confirmed Alzheimer's disease and dementia with Lewy bodies in Japan. Dement Geriatr Cogn Disord 22:216-222.

Alonso M, Vianna MR, Depino AM, Mello e Souza T, Pereira P, Szapiro G, Viola H, Pitossi F, Izquierdo I, Medina JH (2002) BDNF-triggered events in the rat hippocampus are required for both short- and long-term memory formation. Hippocampus 12:551-560.

Andersen OM, Reiche J, Schmidt V, Gotthardt M, Spoelgen R, Behlke J, von Arnim CA, Breiderhoff T, Jansen P, Wu X, Bales KR, Cappai R, Masters CL, Gliemann J, Mufson EJ, Hyman BT, Paul SM, Nykjaer A, Willnow TE (2005) Neuronal sorting protein-related receptor sorLA/LR11 regulates processing of the amyloid precursor protein. Proc Natl Acad Sci U S A 102:13461-13466.

Bettens K, Brouwers N, Engelborghs S, De Deyn PP, Van Broeckhoven C, Sleegers K (2008) SORL1 is genetically associated with increased risk for late-onset Alzheimer disease in the Belgian population. Hum Mutat 29:769-770.

Böhm C, Seibel NM, Henkel B, Steiner H, Haass C, Hampe W (2006) SorLA signaling by regulated intramembrane proteolysis. J Biol Chem 281: 14547-14553.

Bothwell M (2006) Evolution of the neurotrophin signaling system in invertebrates. Brain Behav Evol 68:124-132.

Chao MV (2003) Neurotrophins and their receptors: a convergence point for many signalling pathways. Nat Rev Neurosci 4:299-309.

Connor B, Young D, Yan Q, Faull RL, Synek B, Dragunow M (1997) Brainderived neurotrophic factor is reduced in Alzheimer's disease. Brain Res Mol Brain Res 49:71-81.

Crowley C, Spencer SD, Nishimura MC, Chen KS, Pitts-Meek S, Armanini MP, Ling LH, McMahon SB, Shelton DL, Levinson AD, Phillips HS (1994) Mice lacking nerve growth factor display perinatal loss of sensory and sympathetic neurons yet develop basal forebrain cholinergic neurons. Cell 76:1001-1011.

Desai P, Nebes R, DeKosky ST, Kamboh MI (2005) Investigation of the effect of brain-derived neurotrophic factor (BDNF) polymorphisms on the risk of late-onset Alzheimer's disease (AD) and quantitative measures of AD progression. Neurosci Lett 379:229-234.

Dodson SE, Gearing M, Lippa CF, Montine TJ, Levey AI, Lah JJ (2006) LR11/SorLA expression is reduced in sporadic Alzheimer disease but not in familial Alzheimer disease. J Neuropathol Exp Neurol 65:866-872.

Dodson SE, Andersen OM, Karmali V, Fritz JJ, Cheng D, Peng J, Levey AI, Willnow TE, Lah JJ (2008) Loss of LR11/SORLA enhances early pathol- 
ogy in a mouse model of amyloidosis: evidence for a proximal role in Alzheimer's disease. J Neurosci 28:12877-12886.

Ernfors P, Lee KF, Jaenisch R (1994) Mice lacking brain-derived neurotrophic factor develop with sensory deficits. Nature 368:147-150.

Ferrer I, Goutan E, Marín C, Rey MJ, Ribalta T (2000) Brain-derived neurotrophic factor in Huntington disease. Brain Res 866:257-261.

Games D, Adams D, Alessandrini R, Barbour R, Berthelette P, Blackwell C, Carr T, Clemens J, Donaldson T, Gillespie F, Guido T, Hagopian S, Johnson-Wood K, Khan K, Lee M, Leibowitz P, Lieberburg I, Little S, Masliah E, McConlogue L, et al. (1995) Alzheimer-type neuropathology in transgenic mice overexpressing V717F beta-amyloid precursor protein. Nature 373:523-527.

Ge YW, Lahiri DK (2002) Regulation of promoter activity of the APP gene by cytokines and growth factors: implications in Alzheimer's disease. Ann N Y Acad Sci 973:463-467.

Hall J, Thomas KL, Everitt BJ (2000) Rapid and selective induction of BDNF expression in the hippocampus during contextual learning. Nat Neurosci 3:533-535.

Howells DW, Porritt MJ, Wong JY, Batchelor PE, Kalnins R, Hughes AJ, Donnan GA (2000) Reduced BDNF mRNA expression in the Parkinson's disease substantia nigra. Exp Neurol 166:127-135.

Knusel B, Gao H, Okazaki T, Yoshida T, Mori N, Hefti F, Kaplan DR (1997) Ligand-induced down-regulation of Trk messenger RNA, protein and tyrosine phosphorylation in rat cortical neurons. Neuroscience 78:851862.

Lee JH, Chulikavit M, Pang D, Zigman WB, Silverman W, Schupf N (2007) Association between genetic variants in sortilin-related receptor 1 (SORL1) and Alzheimer's disease in adults with Down syndrome. Neurosci Lett 425:105-109.

Linnarsson S, Björklund A, Ernfors P (1997) Learning deficit in BDNF mutant mice. Eur J Neurosci 9:2581-2587.

Matrone C, Ciotti MT, Mercanti D, Marolda R, Calissano P (2008) NGF and BDNF signaling control amyloidogenic route and Abeta production in hippocampal neurons. Proc Natl Acad Sci U S A 105:13139-13144.

Nagahara AH, Merrill DA, Coppola G, Tsukada S, Schroeder BE, Shaked GM, Wang L, Blesch A, Kim A, Conner JM, Rockenstein E, Chao MV, Koo EH, Geschwind D, Masliah E, Chiba AA, Tuszynski MH (2009) Neuroprotective effects of brain-derived neurotrophic factor in rodent and primate models of Alzheimer's disease. Nat Med 15:331-337.

Narisawa-Saito M, Wakabayashi K, Tsuji S, Takahashi H, Nawa H (1996) Regional specificity of alterations in NGF, BDNF and NT-3 levels in Alzheimer's disease. Neuroreport 7:2925-2928.

Nyborg AC, Ladd TB, Zwizinski CW, Lah JJ, Golde TE (2006) Sortilin, SorCS1b, and SorLA Vps10p sorting receptors, are novel gammasecretase substrates. Mol Neurodegener 1:3.

Offe K, Dodson SE, Shoemaker JT, Fritz JJ, Gearing M, Levey AI, Lah JJ (2006) The lipoprotein receptor LR11 regulates amyloid beta production and amyloid precursor protein traffic in endosomal compartments. J Neurosci 26:1596-1603.
Reichardt LF (2006) Neurotrophin-regulated signalling pathways. Philos Trans R Soc Lond B Biol Sci 361:1545-1564.

Rogaeva E, Meng Y, Lee JH, Gu Y, Kawarai T, Zou F, Katayama T, Baldwin CT, Cheng R, Hasegawa H, Chen F, Shibata N, Lunetta KL, PardossiPiquard R, Bohm C, Wakutani Y, Cupples LA, Cuenco KT, Green RC, Pinessi L, et al. (2007) The neuronal sortilin-related receptor SORL1 is genetically associated with Alzheimer disease. Nat Genet 39:168-177.

Rohe M, Carlo AS, Breyhan H, Sporbert A, Militz D, Schmidt V, Wozny C, Harmeier A, Erdmann B, Bales KR, Wolf S, Kempermann G, Paul SM, Schmitz D, Bayer TA, Willnow TE, Andersen OM (2008) Sortilinrelated receptor with A-type repeats (SORLA) affects the amyloid precursor protein-dependent stimulation of ERK signaling and adult neurogenesis. J Biol Chem 283:14826-14834.

Ruiz-León Y, Pascual A (2004) Regulation of beta-amyloid precursor protein expression by brain-derived neurotrophic factor involves activation of both the Ras and phosphatidylinositide 3-kinase signalling pathways. J Neurochem 88:1010-1018.

Scherzer CR, Offe K, Gearing M, Rees HD, Fang G, Heilman CJ, Schaller C, Bujo H, Levey AI, Lah JJ (2004) Loss of apolipoprotein E receptor LR11 in Alzheimer disease. Arch Neurol 61:1200-1205.

Schilling G, Becher MW, Sharp AH, Jinnah HA, Duan K, Kotzuk JA, Slunt HH, Ratovitski T, Cooper JK, Jenkins NA, Copeland NG, Price DL, Ross CA, Borchelt DR (1999) Intranuclear inclusions and neuritic aggregates in transgenic mice expressing a mutant $\mathrm{N}$-terminal fragment of huntingtin. Hum Mol Genet 8:397-407.

Schindowski K, Belarbi K, Buée L (2008) Neurotrophic factors in Alzheimer's disease: role of axonal transport. Genes Brain Behav 7 [Suppl 1]:43-56.

Schmidt V, Sporbert A, Rohe M, Reimer T, Rehm A, Andersen OM, Willnow TE (2007) SorLA/LR11 regulates processing of amyloid precursor protein via interaction with adaptors GGA and PACS-1. J Biol Chem 282:32956-32964.

Siegel GJ, Chauhan NB (2000) Neurotrophic factors in Alzheimer's and Parkinson's disease brain. Brain Res Brain Res Rev 33:199-227.

Spires TL, Grote HE, Varshney NK, Cordery PM, van Dellen A, Blakemore C, Hannan AJ (2004) Environmental enrichment rescues protein deficits in a mouse model of Huntington's disease, indicating a possible disease mechanism. J Neurosci 24:2270-2276.

Tapia-Arancibia L, Aliaga E, Silhol M, Arancibia S (2008) New insights into brain BDNF function in normal aging and Alzheimer disease. Brain Res Rev 59:201-220.

Willnow TE, Petersen CM, Nykjaer A (2008) VPS10P-domain receptorsregulators of neuronal viability and function. Nat Rev Neurosci 9:899-909.

Zuccato C, Ciammola A, Rigamonti D, Leavitt BR, Goffredo D, Conti L, MacDonald ME, Friedlander RM, Silani V, Hayden MR, Timmusk T, Sipione S, Cattaneo E (2001) Loss of huntingtin-mediated BDNF gene transcription in Huntington's disease. Science 293:493-498. 